\title{
Information Literacy Assessment for Instruction Improvement and Demonstration of Library Value: Comparing Locally-Grown and Commercially-Created Tests
}

\author{
Kathy Clarke \\ James Madison University, USA \\ Carolyn Radcliff \\ Carrick Enterprises, USA
}

\begin{abstract}
This paper describes two types of fixed-choice information literacy tests, one locally created and one nationally developed. The Madison Research Essentials Skills Test (MREST) is part of a tutorial-test model for first-year library instruction at James Madison University. Students must pass the test before they can move to sophomore status. This testing process relies on a collaborative model between JMU Libraries, the General Education program, and the Center for Assessment Research Studies (CARS). On the national level, the recently created Threshold Achievement Test for Information Literacy (TATIL) is based on the ACRL Framework for Information Literacy and in four test modules measures both information literacy knowledge and dispositions. TATIL was created by librarians and other educators and can be used to guide instructional program changes, for external and internal reporting and to give students recommendations for improving their information literacy. The decision to use a test and to choose which approach to take can be informed by comparing the benefits and limitations of these testing options.
\end{abstract}

Tests have been used to assess information literacy for many years. Whether it is a quick test created for local use after instructional sessions, an institutional test to ensure that skills have been acquired or for longitudinal study of student knowledge, or a standardized test offering multi-institutional comparisons of results, this assessment method has a long history and a strong presence in library assessment. This paper explores two types of fixed-choice tests, one locally created and one commercially sponsored, which can be used for program improvement.

Fixed-choice tests are one method among many for assessing achievement and ability. The benefits and limitations of standardized tests are well documented. ${ }^{1}$ Despite criticisms, tests are in wide use by colleges and universities, professional organizations, and testing companies. Well-written tests are effective, versatile, and can measure both lower-order and higher-order thinking skills. ${ }^{2}$ Fixed-choice tests are relatively easy to administer and use a format that students are familiar with. They offer an efficient way to conduct large-scale assessment and typically provide results both for individual students and for groups of students such as seniors, science majors, or student athletes. Test results facilitate comparisons among groups and across time and ideally suggest improvements to instruction programs that will lead to improved learning outcomes.

Fixed-choice tests come with challenges and assumptions as well. For information literacy testing that is not graded as part of a course, test-takers may lack the motivation to try their best, thereby producing results that do not fully reflect their knowledge and abilities. Test designers can address this challenge with appropriate messages and other techniques. Costs associated with testing can act as a barrier, whether those costs are time, expertise, or money. 


\section{Locally-Created Tests: James Madison University's MREST}

At James Madison University, first-year library instruction is handled via a tutorial-test model within the General Education program's foundational skills courses. The tutorial, Madison Research Essentials, is a combination of video tutorials followed by practice exercises. The test, Madison Research Essentials Skills Test (MREST), is a requirement that all students must successfully meet or face an administrative hold blocking them from sophomore registration. While the tutorials are conceptually presented to cover the outcomes, the test tries to push students to apply the covered concepts with scenarios that compare to real student information literacy challenges.

Approximately 6,000 first-year and transfer students complete the test annually. Data are analyzed for trends in student achievement and areas for improvement. We use MREST scores and subscales to determine which objectives students are struggling with and we make tutorial changes accordingly. By requiring all students to meet this standard, we are setting a competency standard that must be met by the end of the first academic year.

A shorter version of the MREST, InfoCore is one of a battery of tests given on JMU Assessment Days. Incoming first-year students take assessments as a part of their orientation prior to classes and again after completing three semesters. The InfoCore allows us to compare change over time; students do not arrive at JMU with information literacy skills and we show that they make significant gains from first year to sophomore year. This pre-/post-test model, specifically with the same sample of students, shows the gains JMU students are making in this learning domain. Comparing the same cohort of students from first-year to sophomore shows that we are making gains in each objective, some very significant.

These efforts rely on a collaborative model between JMU Libraries, the General Education program, and the Center for Assessment Research Studies (CARS). JMU offers a PhD in assessment and measurement, which creates access to psychometric experts and graduate students.

We follow this learning cycle model:

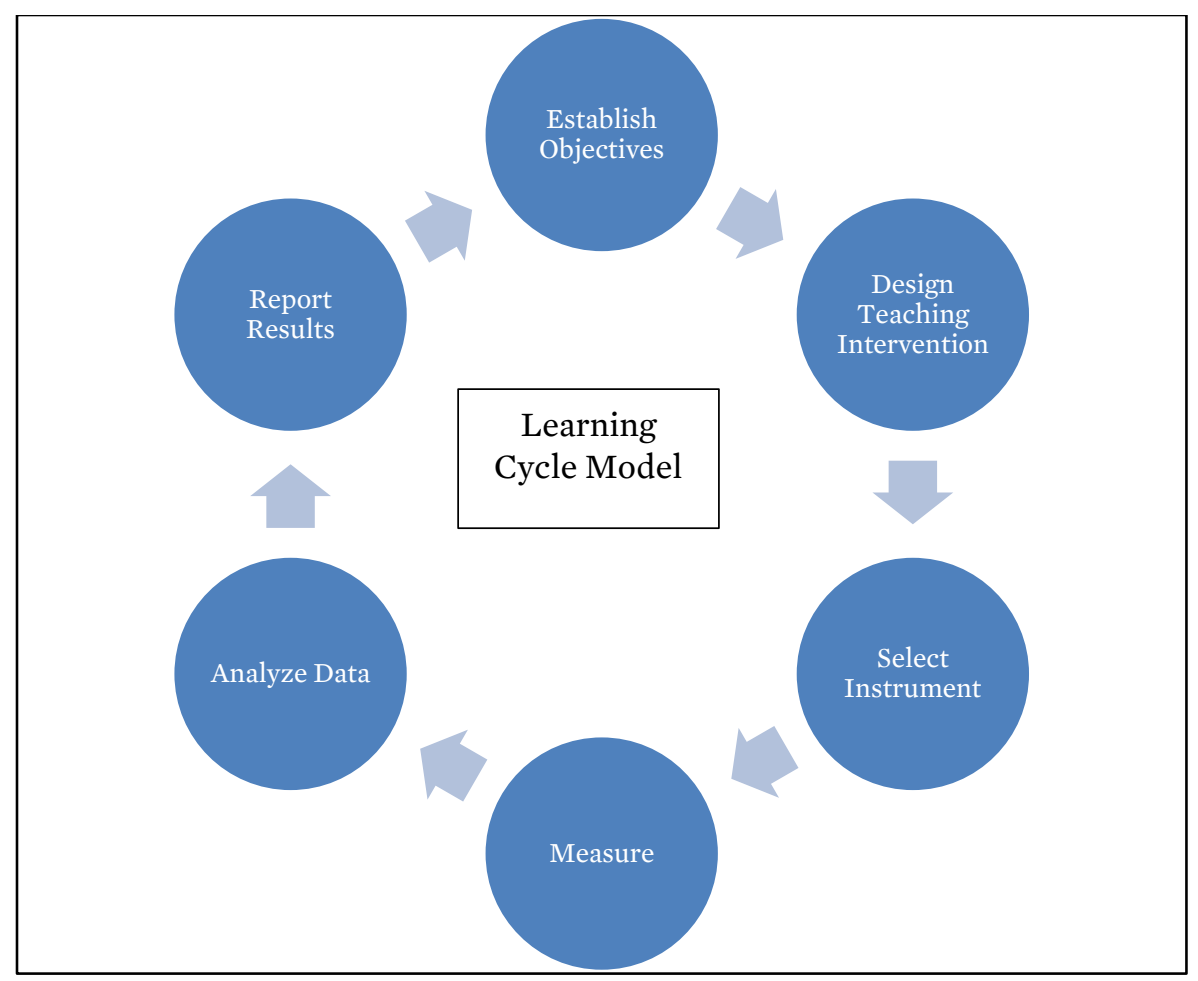




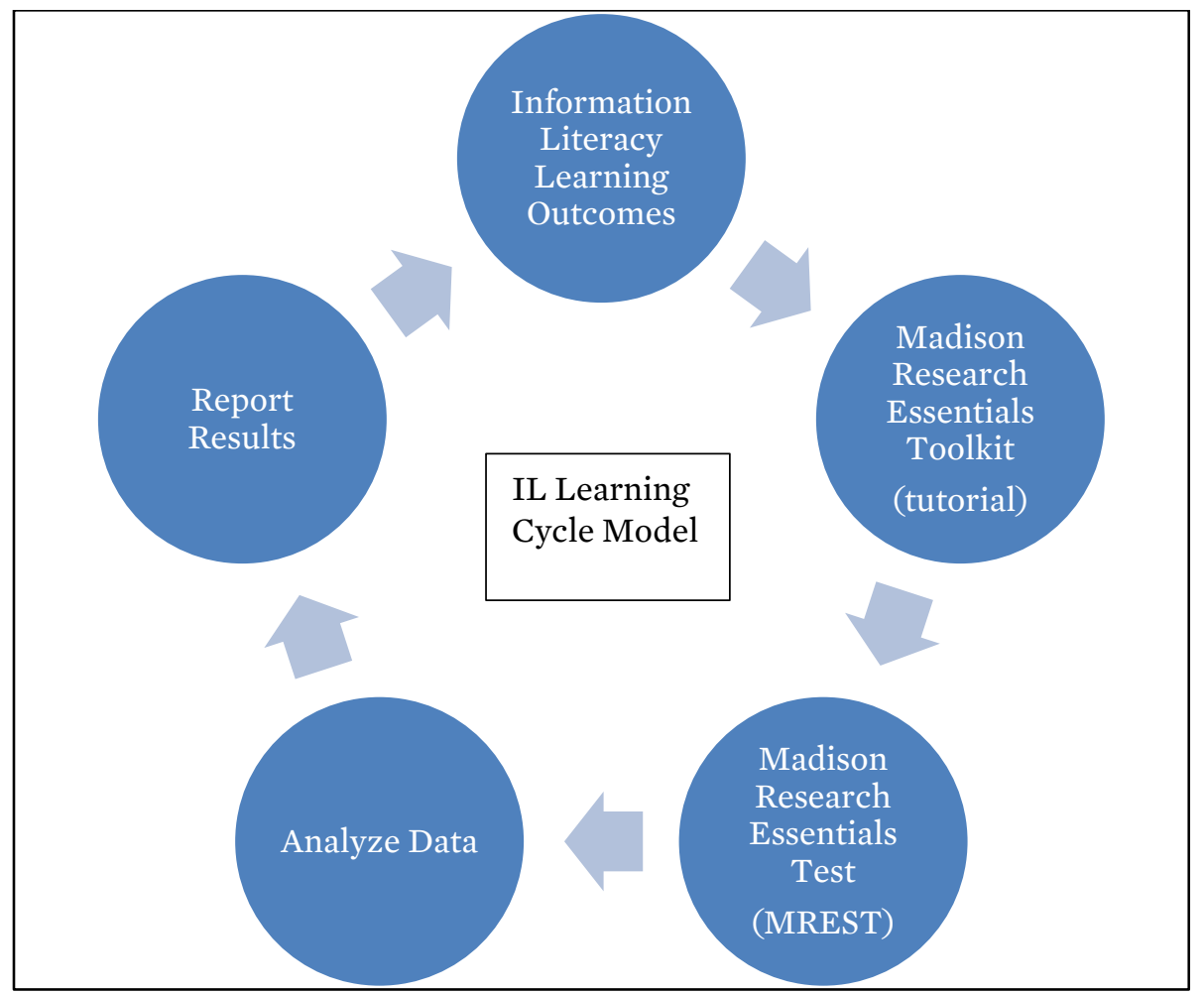

At each level in the cycle, attention is paid to adhering to the outcomes. JMU's information literacy learning outcomes are based on ACRL's Framework for Information Literacy for Higher Education ${ }^{3}$ and are a part of the JMU's General Education curriculum. These outcomes are as follows:

- Recognize the components of scholarly work and that scholarship can take many forms.

- Demonstrate persistence and employ multiple strategies in research and discovery processes.

- Identify gaps in their own knowledge and formulate appropriate questions for investigations in academic settings.

- Evaluate the quality of information and acknowledge expertise.

- Use information effectively in their own work and make contextually appropriate choices for sharing their scholarship.

- Use information ethically and legally.

Incoming students are introduced to the outcomes in the Human Communication course that they must complete in their first year. This course was chosen as the most common course of the core for which students rarely arrive with transfer credit (unlike first-year composition). Students are assigned to view a series of tutorials (available here: https://www.lib.jmu.edu/mretoolkit/), which are also embedded into the course management system (Canvas) for all sections of the SCOM100-level courses (75 sections in the fall, 55 sections in spring). Also embedded in the courses are practice exercises that allow instructors to assign grades and give students an opportunity to practice. After completion of the tutorials, students are directed to complete the Madison Research Essentials Skills Test (MREST). The MREST is given in a proctored computer testing lab and is the only location where students can take the test. Students must meet a competency score or pass at the advanced level, and students are provided their scores at the end of the test. Students who do not pass can take the test as many times as they need to until they pass. Interventions are in place for students who require more assistance. Most students meet the standard by their second attempt. The test is delivered via a homegrown testing platform, Green Test System. The creation of this platform was 
driven by the need to be able to do item performance analysis to ensure the test is reliable and valid. New content or test items are regularly added to the test platform. New items sit on the test as unscored items for a full year so that our psychometric experts can ensure that items are performing effectively and well. Items that do not meet performance indicators are not put on the scored test. This model allows us to reach every student every year with foundational skills. Students who continue at JMU will meet their liaison librarian when they take a research methods course in their major.

The effort is quite remarkable and takes a distributed team of experts to make it work on such a large scale. The first year librarian is responsible for tutorial design and test item writing. Faculty who teach in the basic communication course share their courses with this librarian and she puts all content into their online courses prior to the beginning of the semester. The Center for Assessment Research Studies is home to a programmer who is responsible for the Green Testing System. This programmer works closely with the team that manages the Assessment Testing Lab. He is also responsible for gathering data to report on how students are doing on the test for year-end reporting. General education administrative staff then upload scores onto student transcripts.

The InfoCore measures similar skills but is not a high-stakes test, as there is no reward for doing well on this test. But we can show what set of skills students arrive with and how they change over the course of three semesters. Student scores consistently go up across all objectives as shown below. (Note, this version of InfoCore was based on the ACRL Competency Standards for Information Literacy for Higher Education. ${ }^{4}$ )
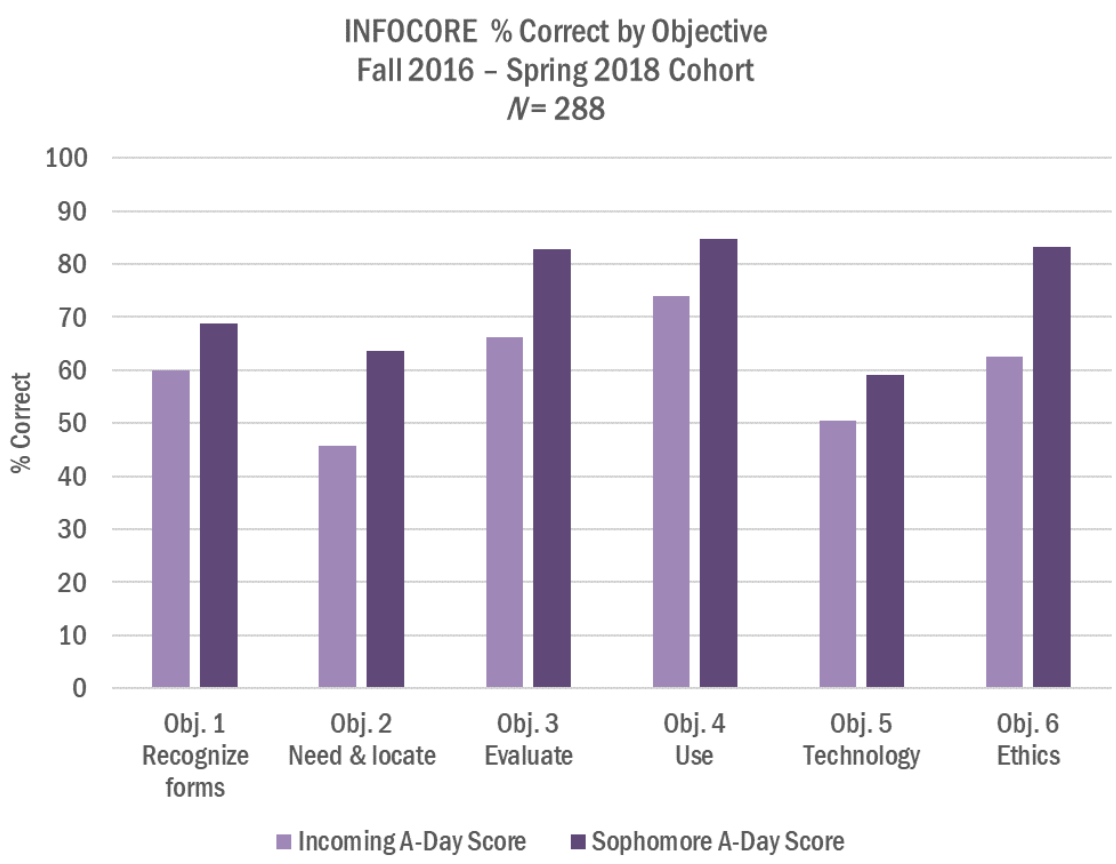

By using some student demographic data, we have been able to find three populations of students who struggle with the MREST; transfer students, international students, and athletes have proven to have more difficulty than average. Interventions have been designed for athletes and international students as they have some special assistance offered to them at JMU. Transfer students are proving more elusive as they typically bounce into majors as they arrive on campus. Our liaison librarians are working with academic departments to help locate those students and provide additional assistance if necessary. We have also discovered where not to apply resources; in 2014, we discovered that students who either never attempt or do not pass the MREST do not return to JMU for their sophomore year. This observation allowed us to make a case for not designing interventions for students who are not able or will not return to JMU. 
A team of faculty including the first year librarian, the foundational skills director, and faculty from the Center for Assessment and Research Studies spend about a month analyzing data from the MREST and InfoCore each summer. We have worked hard to make our reports meaningful and easy to digest, and they are used to ask for resources and tweak our process. The work of writing these reports has paid off; we are being used as a model for assessment reports for other parts of campus.

The drawback to using this model of first-year information literacy instruction is that we do not have anything to compare our students to. We have recently been talking to the creators of TATIL (Threshold Assessment Test for Information Literacy) to see how JMU might be able to compare our scores to national averages or to peer institutions.

In 2018, Virginia's State Council for Higher Education (SCHEV) released a new reporting mandate for public institutions in Virginia. Each institution will be required to report on four learning domains that are standard (civic engagement, writing, critical thinking, and quantitative reasoning) but schools can choose to add additional learning domains. JMU has chosen to include information literacy in a suite of reported learning domains and will use information literacy as one of the first reporting domains, along with quantitative literacy. Schools are being encouraged to make their assessment results easy to find and to understand in order to increase transparency for multiple constituencies, including students and parents.

\section{Commercially-Sponsored Tests}

Several standardized tests for information literacy have been developed in the past two decades, spurred by the publication of information literacy standards by the Association of College and Research Libraries in 2000. Commercial tests include iSkills from the Educational Testing Service (discontinued in 2016), Information Literacy Test (ILT), Standardized Assessment of Information Literacy Skills (SAILS), and the Threshold Achievement Test for Information Literacy (TATIL, https://thresholdachievement.com). The ILT was developed at James Madison University and is now licensed to and available commercially from Madison Assessment (https://www.madisonassessment.com/assessment-testing/information-literacytest/). It is not related to the MREST, described above. SAILS tests were created at Kent State University and are available from Carrick Enterprises (https://www.projectsails.org/site/), which also created TATIL. This section of the paper focuses on TATIL because it is the most current test. It was inspired by the threshold concepts, knowledge practices, and metacognitive approach of the ACRL information literacy framework.

The Threshold Achievement Test investigates college students' information literacy on two dimensions: knowledge and dispositions. The test separates the broad construct of information literacy into four subconstructs that are presented in individual test modules.

\section{Development Process for the Threshold Achievement Test for Information Literacy}

The creation of TATIL was the work of Dr. April Cunningham, a community college librarian who served as project leader, and an advisory board of librarians and other educators, with support from Carrick Enterprises. Preliminary work included building consensus on what is expected of students' information literacy throughout their college careers, studying the ACRL Framework for Information Literacy for Higher Education to decide what information literacy concepts the test would address, and writing performance indicators. The performance indicators served as the basis for each knowledge test question. Details about the test question development process are available on the Information Literacy Assessment blog (see https://www.informationliteracyassessment.com/?p=1001).

A unique feature of TATIL is the attention given to information literacy dispositions, a key element of the ACRL Framework document. The creation of disposition questions for TATIL began with an analysis of the language of the Framework by Hal Hannon, as described in his blog post here:

https://www.informationliteracyassessment.com/?p=739. Dispositions hold great promise for strengthening understanding of student information literacy and promoting the transfer of learning from one information literacy challenge to a novel task or process. In TATIL, dispositions questions are scenarios that include an information literacy challenge with test-takers evaluating a series of possible strategies for addressing the 
challenge. There are no correct answers; the way a student responds to the strategies indicates how strongly disposed they are to certain approaches.

\section{TATIL Modules}

Each of the four test modules of TATIL focuses on one or two well-defined information literacy constructs. Information about each module, presented below, is reprinted from a blog post by the second author. See https://www.informationliteracyassessment.com/?p=1405.

\section{Module 1: Evaluating Process and Authority}

This module combines concepts from two of the ACRL information literacy frames, Authority is Constructed and Contextual and Information Creation as a Process. It focuses on the process of information creation and the constructed and contextual nature of source authority. It assesses how students understand and value authority, how they define their role in evaluating sources, and how they perceive the relative value of different types of sources for common academic needs. It also explores students' metacognition about information literacy dispositions that underlie their behaviors.

\section{Knowledge Outcomes}

- Apply knowledge of source creation processes and context to evaluate the authority of a source.

- Apply knowledge of authority to analyze others' claims and to support one's own claims.

\section{Dispositions}

Students who can evaluate sources based on the processes used to create them are more likely to critically examine the authority of information within a given context, rather than simply using a one-size-fits-all judgment of credibility. Since the credibility of a source is not absolute or stable, and varies, for example, by discourse community, students must be (1) mindful about the processes used to create the information, (2) comfortable with the fact that the same sources may be considered authoritative in one context but not in another, and (3) responsible to their academic community in looking beneath surface-level markers of authority. The test assesses how students understand and value authority, how they define their role in evaluating sources, and how they perceive the relative value of different types of sources for common academic needs.

\section{Disposition 1: Mindful self-reflection}

Learners who are disposed to demonstrate self-reflection when they are evaluating sources of information consistently question their assumptions about what makes a source authoritative. Example behaviors:

- Looking for features that challenge one's assumptions about the trustworthiness of one's preferred sources.

- Questioning one's own assumptions about the reliability of traditional forms of scholarly authority.

- Recognizing when there are good reasons to change one's position on an issue.

\section{Disposition 2: Toleration of ambiguity}

Learners who are disposed to demonstrate toleration for ambiguity when they are evaluating sources of information treat authority as subjective because it is based on the context of the information need. Example behaviors:

- Deciding what to do when authorities disagree.

- Flexibly using traditional and non-traditional information sources at appropriate points in the research process.

- Treating authority as a flexible concept when information needs can only be met with less traditional sources. 
Disposition 3: Responsibility to community

Learners who are disposed to demonstrate a sense of responsibility to their community when they are evaluating sources of information are conscientious about how they invoke authority in order to gain credibility with their audiences. Example behaviors:

- Fulfilling one's responsibility to one's discourse community by using sources carefully.

- Recognizing that the sources one is permitted to use will depend on one's discourse community.

- Taking responsibility for critically evaluating and explaining sources' authority to one's audience when stating and standing by their claims.

Module 2: Strategic Searching

This module relates to the Searching as Strategic Exploration frame. It focuses on the process of planning, evaluating, and revising searches during strategic exploration. It tests students' ability to recall and apply their knowledge of searching. It also explores students' metacognition about information literacy dispositions that underlie their behaviors.

\section{Knowledge Outcomes}

- Plan, conduct, evaluate, and revise searches to achieve relevant results.

- Compare and contrast a range of search tools.

\section{Disposition}

Students who are strategic searchers are more likely to develop a broad repertoire of search techniques because they learn from trial and error and pick up strategies from observing their professors, librarians, and peers. Since searching involves exploration and uncertainty, students must be persistent in order to sustain their searches despite difficulties and frustrations. A disposition toward productive persistence means that students are more likely to satisfy their information needs and keep searching until they find high-quality sources. The test assesses how students understand and value exploration and how they define their role as a searcher.

\section{Disposition 1: Productive persistence}

Learners who are disposed to demonstrate productive persistence during their searches for information approach searching as iterative and not linear by employing alternative strategies and learning from mistakes. Example behaviors:

- Adapting and evolving new strategies rather than clinging to familiar search techniques.

- Handling feelings of frustration that commonly surface during the search process.

- Recovering from a failed search in order to continue searching until the information need is satisfied.

- Taking constructive assignment feedback from instructors as an impetus to continue searching for better sources.

\section{Module 3: Research and Scholarship}

This module combines elements from the Research as Inquiry and Scholarship as a Conversation frames. It focuses on the knowledge-building process and how scholars build knowledge. The test addresses students' ability to apply the research process to their college work in order to participate in the scholarly conversation and assesses how students understand and value their role within the scholarly community. It also explores students' metacognition about information literacy dispositions that underlie their behaviors.

\section{Knowledge Outcomes}

- Understand the processes of scholarly communication and knowledge building.

- Understand stages of the research process. 


\section{Dispositions}

Students who value the role of the research process in building knowledge are more likely to embrace all challenges of the research process, particularly the difficulties of conflicting information and contingent answers because they see research as a process of asking new and better questions as their research progresses. Since research is an iterative process with uncertain outcomes, students must be (1) mindful about the temptation to have their biases confirmed, (2) persistent through the setbacks inherent within the research process, and (3) responsible to their academic community in honoring scholarly ways of knowing and communicating. The test assesses how students understand and value their role within the scholarly community.

\section{Disposition 1: Productive persistence}

Learners who are disposed to demonstrate productive persistence throughout the research process approach inquiry as iterative, adjusting their research question as they learn more. Example behaviors:

- Applying appropriate methods/practices of inquiry regardless of their complexity or negative emotional associations (e.g., frustration).

- Committing to building a knowledge base through background research when exploring an unfamiliar topic.

Disposition 2: Mindful self-reflection

Learners who are disposed to demonstrate self-reflection in the context of research and scholarship consistently question their own assumptions as they are challenged by new knowledge. Example behaviors:

- Spending time exploring a topic with openness and curiosity before committing to a thesis or claim.

- Using critiques from professors, librarians, and peers to improve the quality of their inquiry.

Disposition 3: Responsibility to community

Learners who are disposed to demonstrate a sense of responsibility to the scholarly community recognize and conform to academic norms of knowledge building. Example behaviors:

- Identifying and pursuing appropriate ways to enter the scholarly conversation while still an undergraduate.

- Seeking out and following established models of scholarship and inquiry.

Module 4: The Value of Information

This module is inspired by the Information Has Value frame. It focuses on the norms of academic information creation and the factors that affect access to information. It tests students' ability to recall and apply their knowledge of information rights and responsibilities. It also explores students' metacognition about information literacy dispositions that underlie their behaviors.

\section{Knowledge Outcomes}

- Recognize the rights and responsibilities of information creation.

- Recognize social, legal, and economic factors affecting access to information.

\section{Dispositions}

Students who value information in terms of its accessibility and its role in knowledge-building are more likely to recognize the rights of information creators and the effects of commodifying information, rather than taking the information they find for granted and using it irresponsibly. Since the Internet has made it seem that information is free to create, access, and share, students who value information must be (1) mindful to spot and challenge the negative effects of inequitable distribution of information privilege and (2) responsible to their community by giving credit to intellectual work according to established standards. The test assesses how students understand and value their role within the information ecosystem. 


\section{Disposition 1: Mindful self-reflection}

Learners who are disposed to demonstrate self-reflection in the context of the information ecosystem recognize and challenge information privilege. Example behaviors:

- Considering how to use existing intellectual property to spur creative work without violating the creators' rights.

- Participating in informal networks to reduce disparities caused by the commodification of information.

- Recognizing and suggesting ways to reduce the negative effects of the unequal distribution of information.

Disposition 2: Responsibility to community

Learners who are disposed to demonstrate a sense of responsibility to the scholarly community recognize and conform to academic norms of knowledge building. Example behaviors:

- Accessing scholarly sources through formal channels.

- Avoiding plagiarism in their own work and discouraging plagiarism by others.

- Recognizing the value of their own original contributions to the scholarly conversation.

\section{Uses of TATIL}

TATIL has been adopted by institutions to achieve a variety of local assessment goals. For example, TATIL results, including peer institution comparisons, are being used by one university to inform preparations for institutional reaccreditation. A librarian at another university used TATIL in a 2-credit hour information literacy class within the general education curriculum. Results revealed gaps in critical thinking and problem solving, resulting in an expansion of the course to three credit hours. Because TATIL was completed in 2018 and is fairly new, additional uses of the test will emerge. We can predict some types of usage based on experience with the Project SAILS information literacy test: to track progress from first year to graduation, to guide changes to information literacy programs and sessions, to start conversations with classroom faculty, and to satisfy demands for quantitative assessment data for external and internal reporting.

\section{Comparing the Two Testing Approaches}

In this paper, we described two information literacy tests with an emphasis on test development and use. Below is a summary of the differences between creating a test locally and using a test created by a national organization.

Locally developed tests

- Align with local outcomes and objectives

- Little or no out-of-pocket expenditures

- When done successfully:

- can serve as a model for other campus units

- can reinforce the reputation of the library

- can underscore the value of the library

- can highlight the contributions of the library to both IL and campus-assessment priorities

- may offer clear direction for addressing any deficiencies

Commercially sponsored tests

- Require little local testing expertise

- Reflect national standards and practices

- May align with local outcomes and objectives

- Provide context through benchmarking

- May offer a community of users 
Questions to guide testing decisions

1. What are your specific assessment goals? What questions are you trying to answer?

2. What information do you need in order to answer those questions?

3. What will you do with the results?

4. How will this assessment project benefit a class, a program, or the institution?

5. Who are your potential campus partners?

6. What resources are available? Consider local expertise in test development and evaluation, staff time, and funding.

7. Given answers to these questions, which assessment tools come the closest to meeting your needs? How can you account for any gaps between what the tools provide and what you need?

-Copyright 2019 Kathy Clarke and Carolyn Radcliff

\section{Endnotes}

1. See, for example, Allison Erlinger, "Outcomes Assessment in Undergraduate Information Literacy Instruction: A Systematic Review” College \& Research Libraries 79, no. 4 (May 2018): 442-79.

2. Maryellen Weimer, "Making Multiple-Choice Exams Better," Faculty Focus, March 2, 2018, https://www.facultyfocus.com/articles/educational-assessment/making-multiple-choice-exams-better/; Xiaomeng Xu, Sierra Dawn Kauer, and Samantha Tupy, "Multiple-Choice Questions: Tips for Optimizing Assessment In-Seat and Online," Journal of Scholarship on Teaching and Learning in Psychology 2, no. 2 (June 2016): 147-58, https://doi.org/10.1037/stl0000062; Cynthia J. Brame, "Writing Good Multiple Choice Test Questions," Vanderbilt University Center for Teaching, accessed September 15, 2014, https://cft.vanderbilt.edu//cft/guides-sub-pages/writing-good-multiple-choice-test-questions/; Susan M. Brookhart, How to Assess Higher-order Thinking Skills in Your Classroom (Alexandria, Virginia: ASCD, 2010).

3. Association of College \& Research Libraries, Framework for Information Literacy for Higher Education (Chicago: ACRL, 2015), http://www.ala.org/acrl/standards/ilframework.

4. Association of College \& Research Libraries, "Information Literacy Competency Standards for Higher Education,” accessed September 15, 2018, https://alair.ala.org/handle/11213/7668. 